\title{
Socio-Economic Status and Inequalities in Exposure to Transportation Noise in Hong Kong
}

\author{
Kin-che Lam* and Pak-Kin Chan
}

Department of Geography and Resource Management, The Chinese University of Hong Kong, Hong Kong

\begin{abstract}
Environmental inequality has been validated with social data in many cities worldwide but not in Hong Kong. By applying the latest 3D noise mapping technique and using census data, this study tries to (1) determine the transportation noise exposure of urban inhabitants in Hong Kong; (2) ascertain the extent to which differences in transportation noise exposure are related to the socio-economic status of the inhabitants; and (3) ascertain if socio-economic variations across the city is related to the variations in noise exposure levels associated with varying urban forms and planning history. The results provide evidence for environmental inequality in Hong Kong, showing that noise exposure is weakly but significantly correlated to education attainment and income. Significant differences in socio-economic indicators are also observed among residents of different housing types associated with different time periods. Residents less exposed to road traffic noise are generally in newer buildings, wealthier and better educated.
\end{abstract}

Keywords: Environmental inequality, noise, noise mapping, environmental justice, urban form.

\section{INTRODUCTION}

The term "environmental inequality" refers to "any form of environmental hazard that burdens a particular social group" [1]. Early research on environmental inequality in the 1990s focused largely on the siting of waste facilities and major polluting sources [2], commonly known as locally unwanted land uses (LULU), at locations which are inhabited by the less advantaged groups of the society. In recent years, increasing attention has been given to the unequal exposure of different social groups to environmental nuisances such as air [3, 4], and particularly, noise pollution [3, 5-7].

Noise pollution is very often used as an indicator of environmental quality in the study of environmental inequality because of several reasons. Firstly, noise pollution is a major environmental problem in many cities. Secondly, it is easily quantifiable, either by on-site measurement or modeling, allowing data to be analyzed using various statistical techniques. Thirdly, potential health impacts of excessive exposure to transportation noise are well documented. The potential effects include nuisance, sleep disturbance, stress, impaired mental health and degraded quality of life. The stressrelated health effects can be psychological, behavioral or physiological [8-10]. Some studies have shown that children exposed to excessive transportation noise may suffer from deficits in language skills and speech communication ability $[11,12]$.

Both theoretical and empirical approaches have been adopted to investigate environmental inequality in the past. Theoretical models were adopted largely to explain, or

*Address correspondence to this author at the Department of Geography and Resource Management, The Chinese University of Hong Kong, Hong Kong; E-mail: kinchelam@cuhk.edu.hk reject, some proposed mechanisms of how environmental inequalities have arisen [1,13]. For empirical studies, many focused on a city or a region in which the geographical distribution of pollution and socioeconomic characteristics of the communities were correlated. Such approach focused on the community rather than individual level.

A number of empirical studies have shown that environmental inequalities are evident in many urban communities [14]. For example, Brainard [6] found that some inequality, albeit not a strong one, in noise exposure does exist in the city of Birmingham. Other studies [3, 5, 7] also found that lower socio-economic groups are unfairly exposed to noise.

On the contrary, there are also other studies which do not readily lend support to the inequality phenomenon or its attributed mechanisms. For example, Hite [13] found that in the residence selection process, environmental quality is sometimes being traded for other housing, neighborhood or location characteristics as a result of which the unfair exposure to environmental disamenities for the poor is not evident. Furthermore, based on some longitudinal data, Oakes (SSR 1996) [15] concluded that no significant change over time in the demographic and socioeconomic characteristics of the population living in the area adjoining a locally unwanted facility can be found.

As a city with prevalent pollution problems and diverse urban settings, Hong Kong offers a good opportunity to study environmental inequality. From the environmental perspective, the shortage of space and rapid urbanization has resulted in Hong Kong having an urban acoustic environment dominated by road traffic noise [16-18]. The magnitude of the noise problem is indicated by the estimate that over $18 \%$ of the population is exposed to excessive road traffic noise (HKEPD 2006) [19]. 
The diverse urban form and pattern of development have created a varied environmental setting which allows different factors causing environmental inequality to be elucidated. For example, significant variations in noise levels can be found in different parts of the city that are associated with varying urban forms and planning history [20].

So far, very little research has been carried out in Hong Kong to ascertain if, and to what extent, noise exposure is class-biased and whether the lower socioeconomic stratum is more susceptible than others to poor air quality and environmental noise. Therefore, the primary objective of this study is to ascertain the extent to which differences in road traffic noise exposure are related to the socio-economic status of the inhabitants in urban Hong Kong.

Two key issues which all environmental inequality studies must consider are the unit of study and the method of assessing pollution exposure. Some studies use census enumeration districts $[4,6]$ or small communities as the unit of study. Using this approach, the data are derived from populations instead of individuals. This may lead to the potential problem whereby relationships detected at the population level may not be equally applicable to individual level. Another limitation of this approach is the possible modifiable areal unit problem (MAUP) [21] in which correlations between attributes of study areas are to some extent associated with the size and shape of those study areas.

As regards the assessment methodology, some studies [4, 6] have adopted a modeling approach through which the exposure of the population to pollution in different parts of the city can be assessed cost-effectively. There are of course limitations, such as non-specificity and data uncertainty, in the use of aggregate and simulated data. However, the benefits outweigh the drawbacks particularly if a large city is to be assessed.

To overcome these limitations, an alternative approach can be adopted, which includes undertaking social survey and noise measurement. However, to collect socio-economic data for a large sample size covering individuals with a wide range of various socio-economic variables is extremely time consuming and labor intensive. Also, when individual respondents are the study units, the results will be relatively sensitive to the data provided by each individual and the effect of variation among individuals will be amplified.

Even though using population data is not free of limitations, it nevertheless provides a cost-effective way of assessing the phenomenon of environmental inequality because socio-economic data are readily available from census and bi-census and noise exposure can be modeled and predicted fairly accurately with recent advancement in the 3-D noise mapping technique [20]. Therefore, this research adopts the population-based and noise modeling approach, which has been used by other researchers $[4,6]$, aiming to (1) determine the transportation noise exposure of the urban inhabitants in Hong Kong; (2) ascertain the extent to which differences in transportation noise exposure are related to the socio-economic status of the inhabitants; and (3) ascertain if socio-economic variations across the city is related to the variations in noise levels associated with varying urban forms and planning history [20].

This is the first systematic study to probe into environmental inequalities in Hong Kong with the goal of increasing our understanding of probable differential exposure of the urban population to environmental noise. Such study has theoretical and practical significance in terms of assessment of the efficacy and equity of environmental policies and understanding social class bias in demand for environmental quality. In addition, findings of this research may contribute to the resolution of environmental conflicts for greater social cohesion and promotion of environmental justice.

\section{METHODOLOGY}

The study unit of this research is the street block group (SBG) which is the smallest areal unit in which socioeconomic data from the most recent census in Hong Kong are readily available. These SBGs, with populations ranging from 1,000 to 30,000 , are not large areas with huge populations. Effects of possible MAUP are expected to be minimal.

A total of 117 SBGs were carefully selected for investigation from among the 2,627 SBGs in Hong Kong to represent private housing clusters with different attributes in terms of geographical districts, age, urban forms and socioeconomic characteristics. SBGs containing public housing estates were excluded from this study because the lack of residential mobility disallows dwellers of public housing from moving to quieter areas even if they have the ability to do so [7, 22-24]. This inhibits the factor of residential mobility as an important driving force attributing to environmental inequality. Also, since housing of different ages and forms affect their noise exposure [20], to minimize the variability in noise exposure of dwellings in each individual SBG, only SBGs dominated by one particular housing form or by buildings of similar ages were included in this study, and similar number of SBGs containing old, intermediate, and new housing estates were selected.

Measures of socio-economic characteristics of each SBG were extracted from the latest census in 2001 accessible from the website of a real estate agent [25]. A variety of socioeconomic indicators obtained from the census was used, including education attainment, employment status and monthly income [15].

To perform noise predictions [26, 27], data such as the topography, gradient of roads and footprints and heights of buildings in each SBG were obtained from the Lands Department. Traffic flow data, including vehicular flow, composition of heavy vehicles and traffic speed, were obtained from the Transport Department of the Hong Kong SAR Government for the year 2001 which is the year the most recent census in Hong Kong was undertaken. Air photos were used to check ground conditions and road configuration. Field reconnaissance were also undertaken to check and validate dubious data.

A digital terrain model with roads, buildings and traffic parameters was first built for each SBG using the GIS software ARCVIEW [28]. These terrain models were then used in the noise prediction software LIMA 5.0 [29] to calculate 
the noise exposure of each façade of all buildings in the SBGs following the Calculation of Road Traffic Noise (CRTN) protocol. Noise estimates were undertaken for the peak hour of traffic flow of the day following the same noise assessment procedure of Environmental Protection Department of the Hong Kong SAR Government. The accuracy of the noise prediction software has been validated in previous studies $[28,30]$. Noise mapping results were then displayed on the façade of buildings, using different colors to represent different noise levels, in 3-D format using GIS [30] and the predicted levels were exported to spreadsheets. Since noise exposure of population in a SBG is not uniform, several noise exposure statistical descriptors, including mean, median and percentiles of noise exposure, were calculated in spreadsheets and used for subsequent analyses.

Data analysis focused on elucidating possible differences in noise exposure related to variations in socio-economic indicators. Since there were numerous socio-economic variables from census data, Principal Component Analysis (PCA) were used to combine variables which represent different dimensions of the same parameter before subsequent analyses were performed. Several indicators (including mean, median and percentiles) of noise exposure were also combined using PCA to generate a variable which can encapsulate the different dimensions of the noise exposure situation. This is more representative than the mean or median noise exposure the PCA generated variable takes into account the peak and the background levels. Statistical analyses including linear and stepwise regressions and Analysis Of Variance (ANOVA) were then performed to relate the predicted noise level with difference socioeconomic parameters.

\section{RESULTS}

To quantify the traffic noise exposure of the dwellings in Hong Kong and observe the differences in road traffic noise exposure among residential buildings of different ages and forms, the SBGs were first divided into three groups (Groups $\mathrm{O}$, I and $\mathrm{N}$ ) according to the year of first occupation of the residential buildings. SBGs with majority of the residential buildings first occupied before 1970 belonged to Group O (the oldest group); SBGs dominated by buildings first occupied from 1970 to 1985 were classified into Group I (the intermediate group); Group N (the newest group) contains SBGs with most buildings first occupied after 1985. The cumulative frequencies of the predicted noise levels for these three groups and for all dwellings are shown in Fig. (1).

Road traffic noise exposure of dwellings in Hong Kong generally ranges from 38 to $73 \mathrm{~dB}(\mathrm{~A})$ (Fig. 1). It is clearly observable that the residents in Group N, i.e. the more recent developments, are generally exposed to less road traffic noise than those in Groups $\mathrm{O}$ and I with the maximum exposure up to about $65 \mathrm{~dB}(\mathrm{~A})$ (Fig. 1).

Table 1 shows the results of PCA which combine various indicators of education attainment, employment status, monthly income and predicted noise exposure into four single variables. The factor loadings of all individual variables and the percentages of variance explained by the combined factors are also tabulated in Table $\mathbf{1}$.

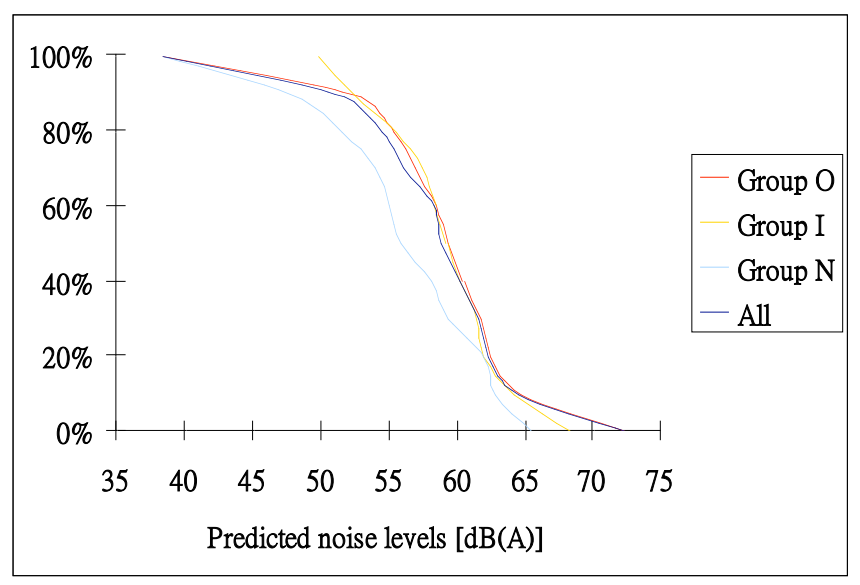

Fig. (1). Cumulative frequencies of predicted noise levels at dwellings in different SBG groups.

In the "combined" variable of education attainment (EA), the factor loadings of "\% primary or lower" and "\% tertiary" are large in magnitude (both > 0.87) but the former is negative while the latter is positive. This means that EA increases with decreasing proportion of population with low education attainment and increasing proportion of population with higher education level. For employment status (ES), similar result is observed. The factor loading of "\% employee" is negative while that of "\% employer" is positive, and both of them are large in magnitude (both >0.86), meaning that they are important indicators of ES. When ES increases, the proportion of working population being employees decreases and the proportion being employers increases. For monthly income (MI) and predicted noise exposure (NE) the factor loadings of all individual variables are positive and large in magnitude (all > 0.72). This means that these individual variables are highly correlated with one another and the magnitudes of the resultant variables MI and NE are generally reflective of the variation in monthly income and noise exposure.

The combined socio-economic variables EA, ES and MI were used as independent variables for linear regression which tried to relate them individually to the dependent variable NE. The results of the linear regressions are summarized in Table $\mathbf{2}$.

Both EA and MI are significantly $(\mathrm{P}<0.04)$ and negatively correlated with NE (Table 2 ) although the $\mathrm{R}^{2}$ values are low (both < 0.05). This means that noise exposure is generally higher for those with lower education attainment and income although the relationship is not strong. ES is not significantly correlated with $\mathrm{NE}$ with very high $\mathrm{P}$ value $(\mathrm{P}>$ $0.95)$. This means that noise exposure is independent of employment status.

Stepwise regression was also performed, trying to fit all three socio-economic variables simultaneously into the regression model. However, only MI was included in the stepwise regression model, the equation of which was the same as the last equation shown in Table 2. Such result is obtained probably because MI is closely correlated with the 
Table 1. List of Combined Variables and the Descriptions and Factor Loadings of their Individual Component Variables as Combined by Principle Component Analysis

\begin{tabular}{|c|c|c|c|c|}
\hline $\begin{array}{l}\text { Combined Vari- } \\
\text { able (by PCA) }\end{array}$ & $\begin{array}{l}\text { Individual Variable } \\
\text { (from Census Data) }\end{array}$ & $\begin{array}{l}\text { Definition of Individual Variables as Described } \\
\text { in the Census of } 2001 \text { in Hong Kong }\end{array}$ & $\begin{array}{l}\text { Factor Loading of } \\
\text { Individual Variable }\end{array}$ & $\begin{array}{l}\% \text { Variance Explained } \\
\text { by Combined Variable }\end{array}$ \\
\hline \multirow{3}{*}{$\begin{array}{l}\text { Education attain- } \\
\text { ment } \\
\text { (EA) }\end{array}$} & $\%$ primary or lower & $\begin{array}{c}\text { Percentage of population with aged } 15 \text { and above } \\
\text { whose highest education attainment is primary } \\
\text { school or lower (or equivalent) in the street block } \\
\text { group }\end{array}$ & -0.875 & \multirow{3}{*}{63.849} \\
\hline & $\begin{array}{l}\% \text { secondary or ma- } \\
\text { triculation }\end{array}$ & $\begin{array}{c}\text { Percentage of population with aged } 15 \text { and above } \\
\text { whose highest education attainment is secondary } \\
\text { school or matriculation (or equivalent) in the } \\
\text { street block group }\end{array}$ & -0.395 & \\
\hline & $\%$ tertiary & $\begin{array}{c}\text { Percentage of population with aged } 15 \text { and above } \\
\text { whose highest education attainment is tertiary } \\
\text { level or above (or equivalent) in the street block } \\
\text { group }\end{array}$ & 0.997 & \\
\hline \multirow{3}{*}{$\begin{array}{l}\text { Employment status } \\
\text { (ES) }\end{array}$} & $\%$ employees & $\begin{array}{l}\text { Percentage of working population who are em- } \\
\text { ployees in the street block group }\end{array}$ & -0.998 & \multirow{3}{*}{63.734} \\
\hline & $\%$ employers & $\begin{array}{l}\text { Percentage of working population who are em- } \\
\text { ployers in the street block group }\end{array}$ & 0.864 & \\
\hline & $\begin{array}{l}\% \text { others (self- } \\
\text { employed/unpaid } \\
\text { family workers) }\end{array}$ & $\begin{array}{c}\text { Percentage of working population who are neither } \\
\text { employees nor employers (including self- } \\
\text { employed and unpaid family workers) in the } \\
\text { street block group }\end{array}$ & 0.412 & \\
\hline \multirow{3}{*}{$\begin{array}{l}\text { Monthly income } \\
\text { (MI) }\end{array}$} & Upper quartile & $\begin{array}{l}\text { Upper quartile of monthly income from main } \\
\text { employment of working population in the street } \\
\text { block group }\end{array}$ & 0.901 & \multirow{3}{*}{76.800} \\
\hline & Median & $\begin{array}{l}\text { Median of monthly income from main employ- } \\
\text { ment of working population in the street block } \\
\text { group }\end{array}$ & 0.982 & \\
\hline & Lower quartile & $\begin{array}{l}\text { Lower quartile of monthly income from main } \\
\text { employment of working population in the street } \\
\text { block group }\end{array}$ & 0.726 & \\
\hline \multirow{4}{*}{$\begin{array}{l}\text { Predicted noise } \\
\text { exposure } \\
\text { (NE) }\end{array}$} & $10 \%$ exceedance & $\begin{array}{l}\text { Noise level in which the predicted noise exposure } \\
\text { of } 10 \% \text { of the dwelling units in the street block } \\
\text { group exceed this level and } 90 \% \text { under this level }\end{array}$ & 0.878 & \multirow{4}{*}{87.535} \\
\hline & $\begin{array}{l}50 \% \text { exceedance } \\
\quad \text { (median) }\end{array}$ & $\begin{array}{l}\text { Noise level in which the predicted noise exposure } \\
\text { of } 50 \% \text { of the dwelling units in the street block } \\
\text { group exceed this level and } 50 \% \text { under this level }\end{array}$ & 0.968 & \\
\hline & $90 \%$ exceedance & $\begin{array}{l}\text { Noise level in which the predicted noise exposure } \\
\text { of } 90 \% \text { of the dwelling units in the street block } \\
\text { group exceed this level and } 10 \% \text { under this level }\end{array}$ & 0.894 & \\
\hline & Mean & $\begin{array}{l}\text { The arithmetic mean of all predicted noise expo- } \\
\text { sure of all dwelling units in the street block group }\end{array}$ & 0.998 & \\
\hline
\end{tabular}

other two socio-economic variables as is confirmed by the correlation matrix shown in Table $\mathbf{3}$. In fact, the three socioeconomic variables EA, ES and MI are all significantly intercorrelated $(\mathrm{P}<0.003)$ with positive correlation coefficients (Table 3). This means that, in general, when the education level is higher, the proportion of employers and the income also tend to be higher. However, the correlation between EA and MI is very strong (correlation coefficient > 0.91) but those between ES and the other two socio-economic variables are relatively weaker (correlation coefficients < 0.50 ).

To ascertain if residential buildings of different ages and forms are different in noise exposure and their dwellings'
Table 2. Linear Regression Models for Predicted Noise Levels Against Different Socio-Economic Variables

\begin{tabular}{|c|c|c|c|}
\hline & Linear Regression Equation & Adjusted $\mathbf{R}^{2}$ & P Value \\
\hline \hline 1 & $\mathrm{NE}=1.48 \times 10^{-15}-0.200 \mathrm{EA}$ & 0.032 & $0.031^{*}$ \\
\hline 2 & $\mathrm{NE}=1.54 \times 10^{-15}-0.005 \mathrm{ES}$ & 0.000 & 0.956 \\
\hline 3 & $\mathrm{NE}=1.54 \times 10^{-15}-0.224 \mathrm{MI}$ & 0.042 & $0.015^{*}$ \\
\hline
\end{tabular}

socio-economic characteristics, ANOVA and post hoc Tukey test were undertaken to differentiate the three groups of 
Table 3. Pearson Correlation Matrix of Different SocioEconomic Variables

\begin{tabular}{|c|c|c|c|c|}
\hline \multirow{2}{*}{} & \multicolumn{2}{|c|}{ ES } & \multicolumn{2}{c|}{ MI } \\
\cline { 2 - 5 } & $\begin{array}{c}\text { Pearson } \\
\text { Correlation } \\
\text { Coefficient }\end{array}$ & P Value & $\begin{array}{c}\text { Pearson } \\
\text { Correlation } \\
\text { Coefficient }\end{array}$ & P Value \\
\hline \hline EA & 0.400 & $0.000^{*}$ & 0.915 & $0.000^{*}$ \\
\hline ES & & & 0.288 & $0.002^{*}$ \\
\hline
\end{tabular}

* Statistically significant with confidence interval of $95 \%$.

SBGs (Groups O, I and N) in terms of EA, ES, MI and NE. The results are summarized in Table $\mathbf{4}$ and the means and associated standard errors of the four variables in each group are illustrated in Fig. (2).

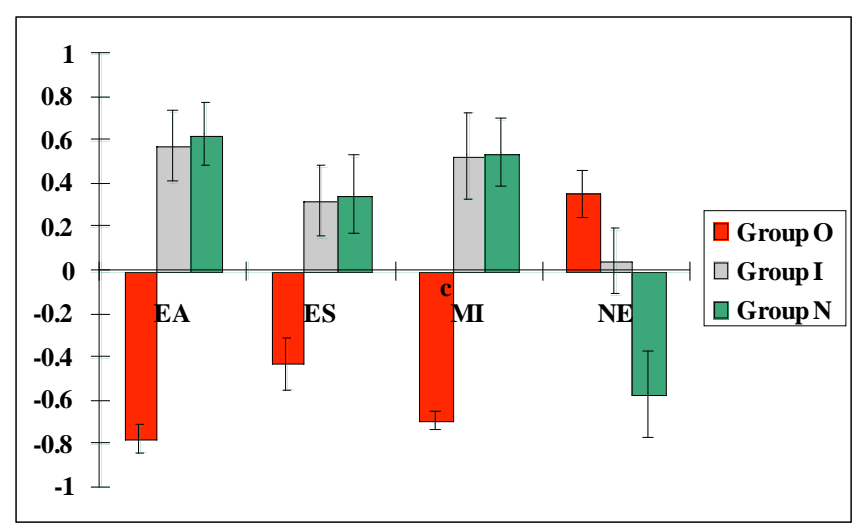

Fig. (2). Means and standard errors of different variables in different SBG groups.

In general, EA, ES and MI increase while NE decreases from Group O to Group I, and then to Group N (Fig. 2). Group $\mathrm{O}$ is distinctly different from Groups $\mathrm{I}$ and $\mathrm{N}$ in terms of all three socio-economic variables $(\mathrm{P}<0.02)$. The dwellings in Group $\mathrm{O}$ had significantly lower education attainment, smaller proportion of employers and lower income compared to those in Groups I and N, in which no significant difference in terms of these socio-economic variables is observable ( $\mathrm{P}>0.32$ ). However, noise exposure of Group $\mathrm{N}$ is significantly lower than that in Group I ( $\mathrm{P}<0.03)$, which is not significantly different from Group $\mathrm{O}$ in terms of noise exposure of dwellings $(\mathrm{P}>0.60)$.

\section{DISCUSSION}

Findings of this research reconfirm the results of a previous study on the differences in road traffic noise exposure among different housing types in Hong Kong [30]. In general, the housing design and morphology of the residential buildings in Hong Kong is a good predictor of the age of the buildings because different designs were popular at different time periods. Therefore, the classification of buildings using the age in this study also represents a classification in different housing forms.

In general, the road traffic noise exposure of dwellings in Hong Kong ranges from 38 to $73 \mathrm{~dB}(\mathrm{~A})$ (Fig. 1). However, new residential buildings first occupied after 1985 are significantly quieter than older ones, with the maximum exposure only up to only about $65 \mathrm{~dB}(\mathrm{~A})$ (Fig. 1). This shows an improvement in building design with time in order to reduce noise exposure of dwellings.

Results of linear regression show that education attainment and monthly income are both related to noise exposure, with higher education level and income exposed to less noise (Table 2). This means that environmental inequality does exist in Hong Kong, with people of lower socio-economic status generally exposed to more road traffic noise. However, environmental inequality is not very serious in Hong Kong because the relationship as shown in the linear regression is not very strong with small $\mathrm{R}^{2}$ values (Table 2 ).

The major driving force of environmental inequality in terms of road traffic noise exposure is probably the differences in financial status of the residents as revealed by the results of stepwise regression in which monthly income was the only factor included in the stepwise regression model. This supports the notion that people with better financial status tend to "buy" themselves out of the noisy neighborhood [7] while those who are less able to do so have to tolerate the lower environmental quality [22-24].

Table 4. Results of post hoc Tukey Test on Different Variables Among Different SBG Groups

\begin{tabular}{|c|c|c|c|c|c|}
\hline & & \multicolumn{2}{|c|}{ Group I } & \multicolumn{2}{|c|}{ Group N } \\
\hline & & Mean Difference & P Value & Mean Difference & P Value \\
\hline \multirow{2}{*}{ EA } & Group 0 & -1.279 & $0.000 *$ & -1.344 & $0.000^{*}$ \\
\hline & Group I & & & -0.065 & 0.936 \\
\hline \multirow{2}{*}{ ES } & Group O & -0.639 & $0.010^{*}$ & -0.648 & $0.008 *$ \\
\hline & Group I & & & -0.009 & 0.999 \\
\hline \multirow{2}{*}{ MI } & Group O & -1.201 & $0.000^{*}$ & -1.466 & $0.000 *$ \\
\hline & Group I & & & -0.265 & 0.323 \\
\hline \multirow{2}{*}{$\mathbf{N E}$} & Group O & 0.322 & 0.279 & 0.924 & $0.000^{*}$ \\
\hline & Group I & & & 0.602 & $0.026^{*}$ \\
\hline
\end{tabular}


Another reason why the other two variables were not included in stepwise regression is that all three socioeconomic variables (EA, ES and MI) in this study are intercorrelated (Table 3). Therefore, in general, people with higher education level and income tend to be exposed to less noise in their dwellings.

The differences in road traffic noise exposure among the three groups of dwellings (Groups $\mathrm{O}, \mathrm{I}$ and $\mathrm{N}$ ) coincide with the variation in socio-economic variables among them, with dwellings of newer residential buildings exposed to less noise having higher education attainment and higher income. However, interestingly, significant difference in socioeconomic status was found between Group O and Groups I and $\mathrm{N}$ while significant difference in noise exposure was found between Groups O and I and Group N (Table 4). Such results can be explained by the following mechanism of unequal noise exposure among different social groups:

1. Housing design has improved over time with noise exposure becoming a concern in the planning process. Significant improvement is evident after the Environmental Protection Department was established in 1986. This accounts for the significant difference between Group $\mathrm{N}$ and Groups $\mathrm{O}$ and $\mathrm{I}$ in terms of road traffic noise exposure.

2. People who have received higher education have more disposal income and can afford newer housing which is better designed against noise and is quieter.

3. People with better financial status tend to avoid older housing developments (Group O) where environmental quality is low and road traffic noise exposure is high. Therefore, there is a significant difference between Group $\mathrm{O}$ and Groups I and N in terms of socioeconomic characteristics of dwellings.

4. Some of the better off people stay in Group I housing where they grew up even though they have the financial ability to move to Group $\mathrm{N}$ housing probably because they find the noise level acceptable or they have adapted to the noise in the long years of residency, while the others moved to Group $\mathrm{N}$ housing where the environment is better and quieter. Therefore, Group I and Group N are not significant different in terms of socio-economic status even though noise exposure is different between them.

There are certainly many factors other than noise exposure that affect people's choice of residency. This proposed mechanism therefore applies only in a general sense but not for individual cases. Also, it applies probably only to road traffic noise but not other environmental nuisances because the pattern of variation of other environmental nuisances and their relationship with building design and morphology could be different from those of road traffic noise. For example, air quality is usually quite uniform in a local scale whilst significant variation may be observed in a regional scale. Such variations also depend on the weather conditions (e.g. wind speed and wind direction) rather than building form and design. Hence, the proposed mechanism has limited explanatory power and is specific to explaining the phe- nomenon of environmental inequality in terms of road traffic noise exposure at a regional level. Further work on exposure to environmental parameters other than noise and inclusion of the publicly funded housing estates is thus warranted.

\section{CONCLUSION}

In summary, variation in road traffic noise exposure in urban dwellings in Hong Kong ranges from 38 to $73 \mathrm{~dB}(\mathrm{~A})$, depending on building design and morphology. Such variation is statistically related to variation in socio-economic status of the residents. The findings lend support to the occurrence of environmental inequality, albeit not a very strong one, in Hong Kong, with people who are less well educated and with lower income exposed to more road traffic noise. Newer and quieter residential buildings are occupied by better educated and wealthy people while the poor are left to put up with the noisy neighborhood in very old dwellings. However, some people choose to stay in dwellings that are not the quietest even though they have the ability to move to better residences because of habituation and adaptation to the environment. The findings also call for further work on exposure to other environmental risks other than road traffic noise exposure in Hong Kong.

By quantifying road traffic noise exposure of dwellings in Hong Kong and relating it to socio-economic status of the residents, this research provides evidence for the phenomenon of environmental inequality and shows that such phenomenon is not serious in Hong Kong. It also contributes to the understanding and explanation of the driving forces and mechanisms of environmental inequality in terms of differential exposure of road traffic noise across different social groups. Findings of this study are insightful to policy decisions aiming at resolving environmental conflicts for greater social cohesion and promoting environmental justice in Hong Kong.

\section{ACKNOWLEDGEMENTS}

The authors would like to thank the Social Science Faculty of The Chinese University of Hong Kong for providing a Direct Grant to support this research.

\section{REFERENCES}

[1] Pellow DN. Environmental Inequality Formation: Towards a Theory of Environmental Injustice. Am Behav Sci 2000; 43: 581-601.

[2] Szasz A, Meuser M. Environmental Inequalities: Literature Review and Proposals for New Directions in Research and Theory. Curr Sociol 1997; 45: 99-120.

[3] Baum A, Garofalo JP, Yali AM. Socioeconomic status and chronic stress: does stress account for SES effects on health? Ann NY Acad Sci 1999; 896: 131-144.

[4] Brainard JS, Jones AP, Bateman IJ, Lovett AA, Fallon PJ. Modelling environmental equity: access to air quality in Birmingham UK. Environ Plan A 2002; 34: 695-716.

[5] Hoffmann B, Robra BP, Swart E. Social inequity and noise pollution by traffic in the living environment: an analysis by the German Federal Health Survey. Gesundheitswesen 2003; 65: 393-401.

[6] Brainard JS, Jones AP, Bateman IJ, Lovett AA. Exposure to environmental urban noise pollution in Birmingham, U.K. Urban Stud 2004; 41: 1581-2600.

[7] Fyhri A, Klaeboe R. Direct, indirect influence of income on road traffic noise annoyance. J Environ Psychol 2006; 26: 27-37.

[8] Stansfeld S, Haines M, Brown B. Noise and health in the urban environment. Rev Environ Health 2000; 15: 43-82. 
[9] Passchier-Vermeer W, Passchier WF. Noise exposure and public health. Environ Health Perspect 2000; 108: 123-131.

[10] Vallet M. Effects of noise on health. In Garcia A, Ed. Environmental Urban Noise, WIT Press, 2001; 64-109.

[11] Berglund B. Aircraft noise and health: Proceedings of $2^{\text {nd }}$ Airport Regions Conference; 1996; 111-740.

[12] Evans GW, Maxwell L. Chronic noise exposure and reading deficits: the mediating effects of language acquisition. Environ Behav 1997; 29: 638-656.

[13] Hite D. A random utility model of environmental equity. Growth Change 2000; 31: 40-58.

[14] Harding AK, Holdren GR. Environmental equity and the environmental professional. Environ Sci Technol 1993; 27: 1990-1993.

[15] Oakes JM, Anderton DL, Anderson AB. A longitudinal analysis of environmental equity in communities with hazardous waste facilities. Soc Sci Res 1996; 25: 125-148.

[16] Brown L, Lam KC. Levels of ambient noise in Hong Kong. Appl Acoust 1987; 20: 85-100.

[17] Lam KC. Traffic Noise in the Eastern District - Survey Report. Consultancy Report submitted to The Eastern District Board, 1988

[18] Lam KC. Traffic and Industrial Noise Pollution in Tsuen Wan. Consultancy Report submitted to the Tsuen Wan District Board, 1996.

[19] Hong Kong Environmental Protection Department. Draft Comprehensive Plan to Tackle Road Traffic Noise, Hong Kong, 2006.

[20] Lam KC, Ma WC, Hui WC, Chan PK. Noise mapping - A planning tool for a sustainable urban fabric: Proceedings of the $5^{\text {th }}$ China Urban Housing Conference 2005; 475-484.
[21] Openshaw S. Concepts and Techniques in Modern Geography 38: The Modifiable Areal Unit Problem; Environmental Publications: Norwich, 1984.

[22] Bullard R. Residential segregation and urban quality of life. In Bryant B, Ed. Environmental Justice: Issues, Policies and Solutions, Island Press, 1995

[23] Hoyt WH, Rosenthal SS. Household location and Tiebout: do families sort according to preferences for locational amenities? J Urban Econ 1997; 42: 159-178.

[24] Bjornskau T. Road traffic change - A catalyst for segregation. Urban Stud 2005; 42: 69-89.

[25] Centamap <http://www.centamap.com>.

[26] Li B, Tao S, Lam KC. Road traffic noise prediction and planning for urban neighbourhood. Urban Environ Ecol (in Chinese) 1999; 12:57-60.

[27] Lam KC, Hui WC. How noisy is our city? In Wong SY, Yan WS Choi CK, Eds. Understanding the Society - the Social Science Perspective (in Chinese), Faculty of Social Science, The Chinese University of Hong Kong, 2005.

[28] Lam KC, Ma WC, Li BG, Yu SP. GIS-based road traffic noise assessment systems: Proceedings of the $19^{\text {th }}$ Annual Conference of the International Association of Impact Assessment; 1999.

[29] Hinton J. A Report on the Production of Noise Maps of the City of Birmingham. Her Majesty's Stationery Office: London, 2000.

[30] Lam KC, Chan PK, Hui WC. How noisy is our city? Urban soundscapes at homes, neighborhood and community levels: Proceedings of InterNoise, 2005

(C) Lam and Chan; Licensee Bentham Open.

This is an open access article distributed under the terms of the Creative Commons Attribution License (http://creativecommons.org/licenses/by/2.5/), which permits unrestrictive use, distribution, and reproduction in any medium, provided the original work is properly cited. 